\title{
两种同域分布的草原蝗虫对植物挥发性化合物的 嗅觉反应*
}

陈湖海 赵云鲜 康 乐 ${ }^{* *}$

(中国科学院动物研究所农业虫鼠害综合治理国家重点实验室, 北京 100080)

\begin{abstract}
摘要亚洲小车蝗(Oedaleus decorus asiaticus B.-Bienko)和鼓翅皱膝蝗(Angaracris barabensis Pall)为内蒙古草原同域分布、生活时间重叠、但食性不同的两种蝗虫, 亚洲 小车蝗为禾草专食者, 鼓翅皱㮏蝗为蓄草专食者. 利用触角电位技术(EAG)比较研究了 这两种蝗虫的雌雄个体对 37 种植物挥发性化合物的嗅觉反应, 结果发现, 这两种蝗虫 的雌雄个体对绿叶挥发化合物的 EAG 反应要高于对萜类及芳香族化合物的反应，其中 6 个碳原子的醇(1-已醇、反-2-已烯-1-醇、顺-2-已烯-1-醇、顺-3-已烯-1-醇)、醛(顺-2已烯-1-醛)、酯(反-3-已烯基乙酸酯), 以及 7 个碳原子的 1-庚醇引起的 EAG 反应最 强; 对具有醇、醛功能团的单萜类化合物的反应高于其他单萜类化合物, 倍半萜类化 合物引起的咱觉反应较低; 在所实验的芳香族化合物中, 苯甲醛引起的反应最强. 对绿 叶挥发化合物的反应, 亚洲小车蝗高于鼓翅皱膝蝗, 亚洲小车蝗雄虫的反应高于其雌 虫, 鼓翅皱㮏蝗无性别差异. 测定两种蝗虫的雌虫对 6 种化合物的剂量反应曲线, 两种 蝗虫对所测化合物的 $\mathrm{EAG}$ 反应浓度为 $10^{-3} \sim 10^{-2} \mathrm{~mol} / \mathrm{L}$, 只有鼓翅皱膝蝗对松油醇的反 应阈浓度为 $10^{-2} \mathrm{~mol} / \mathrm{L}$. 对苯甲醛与正已醛的反应随浓度增加 $\mathrm{EAG}$ 反应增强. 比较触 角不同部分对植物挥发性化合物的 EAG 反应发现, 触角电位反应主要由触角远端的感 器产生, 而非近触角基部的 7 节.
\end{abstract}

\section{关键词 触角电位(EAG) 蝗虫 亚洲小车蝗 鼓翅䏢膝蝗 植物挥发性化合物 同域种}

亚洲小车蝗(Oedaleus decorus asiaticus B.-Bienko)和鼓翅皱膝蝗(Angaracris barabensis Pall)为内蒙古草原重要的害虫 ${ }^{[1]}$, 两者均为旱生种, 选择放牧强度高的生境, 因而成为内蒙古 草原草场退化的指示种 ${ }^{[2]}$. 这两种蝗虫对生境的选择相似, 生活时间重叠, 但食性不同 ${ }^{[1,3]}$, 亚 洲小车蝗为禾草专食者, 而鼓翅皱膝蝗为蒿草专食者, 主要取食菊科和百合科植物. 植食性昆 虫在寻找取食对象时会遇到一系列植物气味, 行为与电生理实验均表明蝗虫可利用植物气味 进行寄主定位 ${ }^{[4 ~ 7]}$.

触角电位技术(electroantennogram, EAG)记录的是触角感器对挥发性化合物的反应. 关于 一些蝗虫对寄主植物的挥发性化合物的触角电位反应已有研究 ${ }^{[4,7 ~ 10]}$. 研究发现, 亚洲小车蝗 和鼓翅皱膝蝗对其寄主植物气味的嗅觉反应不同 ${ }^{[10]}$, 亚洲小车蝗雌虫对禾本科植物的嗅觉反

2003-04-11 收稿

* 中国科学院重要方向项目(批准号: KSCX2-SW-105)、国家自然科学基金重点项目(批准号：39725004)和国家 “九五” 攻关项目 (批准号: 96-016-01-06)资助

**联系人, E-mail: 1kang@panda.ioz.ac.cn 
应明显高于鼓翅皱膝蝗, 而鼓翅皱膝蝗对百合科植物的反应则明显高于亚洲小车蝗, 并且对 菊科植物气味的反应也有高于亚洲小车蝗的趋势，可见，蝗虫的不同食性使之产生对不同寄 主植物气味的适应. 然而, 植物气味是上百种化合物的混合物. 有关这两种草原蝗虫对其中不 同的植物挥发性化合物的嗅觉反应仍需进一步研究. 另外, 以前的研究表明, 亚洲小车蝗与鼓 翅皱膝蝗的触角感器并非均匀分布, 大部分毛型感器、不到 $1 \%$ 的腔雉型感器和少量的雉型感 器分布在触角的近基部 7 节, 腔雉型感器主要分布在触角远端(表 1).

表 1 亚洲小车蝗(雌)和鼓翅皱膝蝗(雌)两个触角片段上的触角感器数量 (Mean $\pm \mathrm{SD}, n=4)$

\begin{tabular}{|c|c|c|c|c|c|c|c|}
\hline \multirow{2}{*}{ 种类 } & \multirow{2}{*}{ 位置 } & \multicolumn{5}{|c|}{ 感器数量 } & \multirow{2}{*}{ 总计 } \\
\hline & & 毛型感器 & 长雉型感器 & 短雉型感器 & 细短雉型感器 & 腔雉型感器 & \\
\hline \multirow[t]{2}{*}{ 亚洲小车蝗 } & 近端 $\leqslant$ 第 7 节 & $23.0 \pm 5.3$ & $77.0 \pm 15.0$ & $87.0 \pm 36.0$ & $12.0 \pm 15.0$ & $2.0 \pm 4.0$ & $200.0 \pm 56.0$ \\
\hline & 远端触角节 & $2.0 \pm 2.8$ & $453.0 \pm 42.0$ & $725.0 \pm 258.0$ & $684.0 \pm 237.0$ & $522.0 \pm 259.6$ & $2385.0 \pm 551.0$ \\
\hline 百分比 $/ \%$ & 近端/整触角 & 92.0 & 14.5 & 10.7 & 1.6 & 0.4 & 7.7 \\
\hline \multirow[t]{2}{*}{ 鼓翅皱膝蝗 } & 近端 $\leqslant$ 第 7 节 & $19.5 \pm 6.8$ & $89.0 \pm 25.0$ & $41.0 \pm 2.0$ & $15.0 \pm 17.0$ & $8.0 \pm 9.6$ & $171.0 \pm 49.0$ \\
\hline & 远端触角节 & $3.0 \pm 4.8$ & $333.0 \pm 64.0$ & $712.0 \pm 128.0$ & $490.0 \pm 61.0$ & $523.5 \pm 201.0$ & $2062.0 \pm 303.0$ \\
\hline 百分比 $1 \%$ & 近端/整触角 & 86.6 & 20.9 & 5.4 & 2.8 & 1.4 & 7.6 \\
\hline
\end{tabular}

本文探讨这两种同域分布、同期发生的蝗虫对植物挥发性物质的嗅觉反应与其食性的关 系，以及触角不同部分由于感器分布的数量与种类的不同对其嗅觉反应的影响.

\section{1 材料与方法}

\section{1 实验昆虫}

亚洲小车蝗、鼓翅皱膝蝗于 1997 年夏采于内蒙古草原中国科学院内蒙古草原生态系统定 位站(北纬 $43^{\circ} 26^{\prime} \sim 44^{\circ} 08^{\prime}$, 东经 $116^{\circ} 04^{\prime} \sim 117^{\circ} 05^{\prime}$ ). 两种蝗虫分笼饲养, 光照周期为 14 ： $10(\mathrm{~L}: \mathrm{D}) \mathrm{h}$, 温度 $28^{\circ} \mathrm{C}$ 左右, 每日饲喂新鲜禾草或蒿草与水, 于捕捉 $15 \mathrm{~d}$ 内用于实验.

\section{2 实验步骤}

共设计 3 组实验: ( i ) 测定亚洲小车蝗与鼓翅皱膝蝗雌雄个体对 37 种植物挥发性化合物 的触角电位反应, 所用标准化合物名称及其纯度、来源见表 2. 将每种标准样品溶于液体石蜡 中, 在旋浴混合器上充分混合, 配成浓度为 $1 \%$ (体积比)的溶液. (ii) 选择 6 种标准化合物, 分 别是绿叶挥发化合物(1-己醇、顺-2-己烯-1-醇、1-辛烯-3-醇、反-3-己烯基乙酸酯)、单萜类化 合物松油醇、芳香族化合物苯甲醛, 配制浓度为 $10^{-5}, 10^{-4}, 10^{-3}, 10^{-2}, 10^{-1} \mathrm{~mol} / \mathrm{L}$ 的溶液用于测 定蝗虫对化合物的剂量反应. (iii) 测定触角的不同部分对 9 种标准样品(1-庚醇、1-已醇、1辛烯-3-醇、顺-2-己烯-1-醇、反-3-己烯基乙酸酯、松油醇、香茅醛, (-)-trans-石竹烯、苯甲醛) 的 $\mathrm{EAG}$ 反应. 将亚洲小车蝗与鼓翅皱膝蝗雌虫的触角一分为二, 一部分为触角近基部 7 节(包 括柄节、梗节及鞭节 1 5 节), 另一部分为剩余的鞭节. 将 $10 \mu \mathrm{L}$ 液体石蜡滴在滤纸条 $(6 \mathrm{~cm} \times$ $0.5 \mathrm{~cm}$ )上为空白刺激, $10 \mu \mathrm{L}$ 的反-3-己烯-1-醇(浓度 $0.1 \mathrm{~mol} / \mathrm{L}$ ) 为标准刺激, 5 次标准样品刺激 之后应用一次空白刺激与标准刺激, 所有标准样品随机刺激触角, 两次刺激间隔至少 $20 \mathrm{~s}$.

\section{3 触角电位 $(\mathbf{E A G})$ 记录}

测定前将蝗虫的一根触角从基部切下, 在双目实体显微镜下将触角端部切下, 在玻璃电 极 (内径 $0.2 \mathrm{~mm}$ ) 内注适量的 Kaissiling 电生理盐水 ${ }^{[10,11]}$, 参考电极插人触角的基部, 记录电极 套在触角的端部. 第 1.2 小节中实验 3 中所需的两个触角片段分别采自两根触角. 玻璃电极中 
表 2 触角电位实验中所用化学样品名称、纯度及来源

\begin{tabular}{|c|c|c|}
\hline 标准化合物名称 & 纯度 $/ \%$ & 来源 \\
\hline \multicolumn{3}{|l|}{ 绿叶挥发化合物 } \\
\hline 1 1-癸醇 1-decanol & 97 & Fluka \\
\hline 2 1-壬醇 1-nonanol & 98 & Fluka \\
\hline 3 1-庚醇 1 -heptanol & 99.5 & Fluka \\
\hline 4 1-己醇 1-hexanol & 99 & Fluka \\
\hline 5 1-戊醇 1-pentanol & 99 & Fluka \\
\hline 6 正丙醇 propyl alcohol & 99.5 & Fluka \\
\hline 7 1-辛烯-3-醇 1-octen-3-ol & 98 & Fluka \\
\hline 8 反-2-已烯-1-醇 Z-hexen-2-ol-1 & 95 & Roth \\
\hline 9 顺-2-己烯-1-醇 E-2-hexen-1-ol & 95 & Fluka \\
\hline 10 顺-3-已烯-1-醇 E-hexen-3-ol-1 & 98 & Roth \\
\hline 11 正己醛 hexanal & 98 & Fluka \\
\hline 12 顺-2-已烯-1-醛 E-2-hexen-1-al & 97 & Fluka \\
\hline 13 2-戊酮 2-pentanone & 99 & Fluka \\
\hline 14 反-3-己烯基乙酸酯 Z-hexen-3-yl acetate & 97 & Roth \\
\hline \multicolumn{3}{|l|}{ 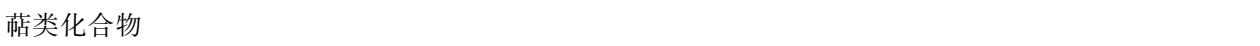 } \\
\hline \multicolumn{3}{|l|}{ 单萜类 monoterpenes } \\
\hline 15 橙花醇 nerol & $90 \sim 95$ & Fluka \\
\hline 16 陇牛儿醇 geraniol & 96 & Fluka \\
\hline 17 （ \pm$)$-里那醇 $\quad( \pm)$-linalool & 97 & Fluka \\
\hline 18 （ \pm$)$ - $\beta$-香茅醇 $\quad( \pm)$ - $\beta$-citronellol & 95 & Fluka \\
\hline 19 松油醇 terpineol & 95 & Roth \\
\hline 20 香茅醛 citronellal & 96 & Roth \\
\hline 21 月桂烯 myrcene & 90 & Roth \\
\hline 22 萜品油烯 terpinolene & 97 & Roth \\
\hline $23 \beta$-蒎烯 $\beta$-pinene & 99 & Roth \\
\hline $24 \alpha$-萜品烯 $\alpha$-terpinene & 92 & Roth \\
\hline $25 \mathrm{R}(-)-\alpha$-采芹烯 $\mathrm{R}(-)-\alpha$-phellandrene & 99 & Fluka \\
\hline 26 (+)-3-苩烯 (+)-3-carene & 99 & Fluka \\
\hline $27 \gamma$-萜品烯 $\gamma$-terpinene & 95 & Fluka \\
\hline $28 \quad(-)-\alpha$-蒎烯 (1s)-(-)- $\alpha$-pinene & 97 & Fluka \\
\hline 29 亖烯 R(+)-limonene & 98 & Fluka \\
\hline \multicolumn{3}{|l|}{ 倍半萜类 sesquiterpenes } \\
\hline 30 法尼醇 farnesol & 95 & Fluka \\
\hline 31 乙酸金合欢酯 farnesyl acetate & 95 & Fluka \\
\hline 32 乙酸里哪(醇)酯 linalyl acetate & 95 & Fluka \\
\hline 33 essigsaure-geranylester & 98 & Fluka \\
\hline $\begin{array}{l}34 \text { (-)-trans-石竹烯(-)-trans-caryophyllene } \\
\text { 芳香族化合物 }\end{array}$ & 99 & Fluka \\
\hline 35 苯甲醛 benzaldehyde & 99 & Fluka \\
\hline 36 乙酸芐酯 benzyl acetate & 99 & Fluka \\
\hline $37 \alpha$-乙酸苯乙酯 $\alpha$-phenylethyl acetate & 99 & Fluka \\
\hline
\end{tabular}

插人直径为 $0.2 \mathrm{~mm}$ 银-氯化银电极, 银-氯化银电极装在微动操作仪上, 后者连接有直流/交流 放大器(Syntech UN-06, 荷兰), 将 EAG 反应信号放大 200 1000 倍, 并在示波器(HAMEG, HM-203-6)上显示, EAG 反应被记录(LM14-204, 上海, 中国)用于数据分析.

\section{4 数据处理}

触角电位 $(\mathrm{EAG})$ 反应值为某个刺激引起的去极化反应值 $(-\mathrm{mV})$ 减去其相邻的空白刺激引 
起的反应 ${ }^{[12]}$, 该值用于分析两个触角片段的 EAG 反应. 在分析蝗虫对 37 种化合物的 EAG 反 应以及剂量反应曲线时, 应用其相对 EAG 值, 即某个刺激的 EAG 值除以标准刺激的 EAG 值 ${ }^{[13]}$, 分析方法为多维方差分析和 LSD 多重分析法 $(P<0.05)$.

\section{2 结果}

\section{1 对 37 种植物挥发性化合物的 EAG 反应}

实验中 37 种标准化合物中的大部分都可使亚洲小车蝗和鼓翅皱膝蝗产生触角电位反应, 而且它们对这些化合物的 EAG 反应趋势相似. 不论雌虫、雄虫, 绿叶挥发气味化合物引起的 触角电位反应均高于萜类化合物. 亚洲小车蝗对这 37 种化合物的反应显著高于鼓翅皱膝蝗 $(P$ $<0.0001$ ). 亚洲小车蝗雄虫的反应高于其雌虫, 而鼓翅皱滕蝗的反应未见雌雄差异(图 1).

\section{2 对绿叶挥发气味的 EAG 反应}

6 个碳原子的醇(1-己醇、反-2-已烯-1-醇、顺-2-己烯-1-醇、顺-3-己烯-1-醇)、醛(顺-2-己 烯-1-醛)、酯(反-3-己烯基乙酸酯), 以及 7 个碳原子的 1-庚醇引起的 EAG 反应最强, 随着碳链 长度的增加或减少 EAG 反应强度减弱(图 1(a) (d)). 亚洲小车蝗的雄虫对绿叶挥发气味的反应 高于其雌虫 $(P<0.05)$, 鼓翅皱膝蝗的反应无雌雄差异.

亚洲小车蝗对 1-癸醇、1-壬醇、1-戊醇、正己醛和反-3-己烯基乙酸酯的反应明显高于鼓 翅皱膝蝗(图 1(a) (d)). 两种蝗虫对顺-2-已烯-1-醇的 EAG 反应高于正已醛(图 1(c)), 对 2-戊酮 的反应显著低于反-3-已烯基乙酸酯 $(P<0.0001$, 图 1(d)).

\section{3 对萜类化合物的反应}

亚洲小车蝗和鼓翅皱膝蝗对具有醇、醛功能团的单萜类化合物的反应高于其他单萜化合 物 $(P<0.05$, 图 $1(\mathrm{e}) \sim(\mathrm{g}))$, 两种蝗虫对萜类化合物的反应没有差异. 亚洲小车蝗雄虫对橙花醇、 月桂烯、萜品油烯、 $\beta$-蒎烯和 $(+)-3$ - 苩烯的反应显著高于其雌虫 $(P<0.05)$. 倍半萜引起的嗅觉 反应较低(图 1(g)), 亚洲小车蝗对(-)-trans-石竹烯的反应高于鼓翅皱膝蝗. 亚洲小车螘雄虫对 乙酸金合欢酯、essigsaure-geranylester 和(-)-trans-石竹烯高于其雌虫. 在 5 种化合物中，两种蝗 虫对乙酸里哪(醇)酯的反应最低.

\section{4 对芳香族化合物的反应}

在所实验的芳香族化合物中, 不同化合物刺激引起的 $\mathrm{EAG}$ 反应差异很大 $(P<0.0001$, 图 $1(\mathrm{~h}))$ ，其中苯甲醛使亚洲小车蝗和鼓翅坡膝蝗的雌虫、雄虫产生的反应最强.

\section{5 对植物挥发性化合物的剂量反应曲线}

在本实验的浓度范围内，随化合物浓度的增加，亚洲小车蝗和鼓翅皱膝蝗的 EAG 反应强 度增加(图 2), 二者的剂量反应曲线相似，它们对所测化合物产生反应的阈浓度为 $10^{-3} \sim 10^{-2}$ $\mathrm{mol} / \mathrm{L}$ ，鼓翅皱膝蝗对松油醇反应的阈浓度 $10^{-2} \sim 10^{-1} \mathrm{~mol} / \mathrm{L}$.

在 $10^{-3} \sim 10^{-1} \mathrm{~mol} / \mathrm{L}$ 浓度范围内蝗虫的触角电位反应迅速增加. 在各浓度下，亚洲小车蝗 雌虫对顺-2-已烯-1-醛的反应高于鼓翅皱膝蝗雌虫，而对其他化合物的反应强度相似. 在低浓 度下 $\left(10^{-4} \sim 10^{-5} \mathrm{~mol} / \mathrm{L}\right)$, 两种蝗虫对 1 -已醇和苯甲醛的反应均高于反-3-己烯基乙酸酯 $(P<$ $0.05)$.

\section{6 触角不同部分对植物挥发性化合物的反应}

将蝗虫的触角一分为二，分别测定它们对标准化合物的 EAG 反应，发现两者有显著差异. 
亚洲小车蝗
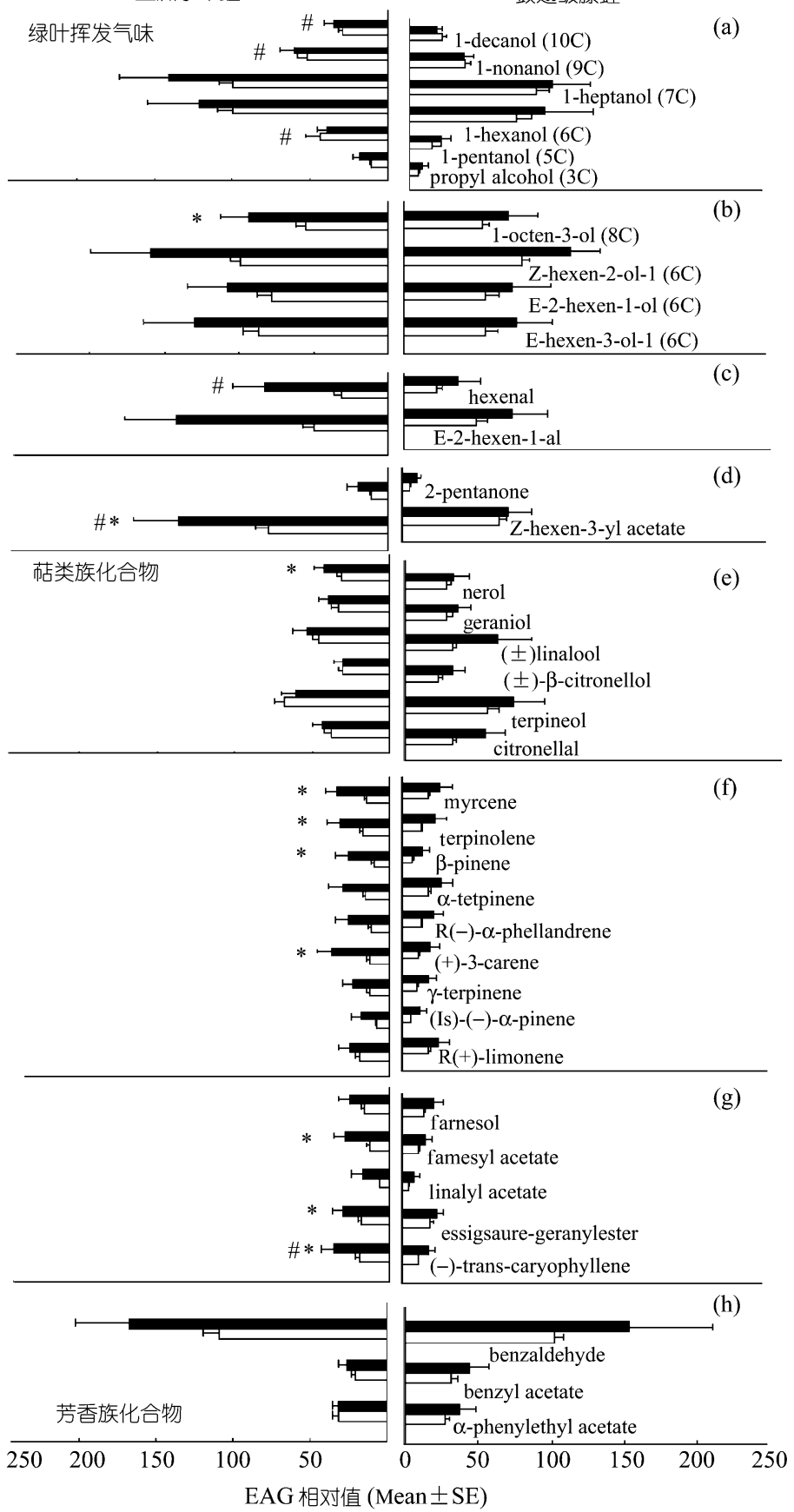

鼓翅皱膝蝗

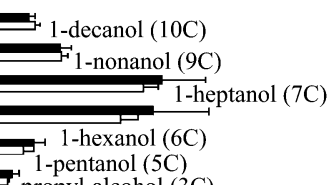

propyl alcohol (3C)

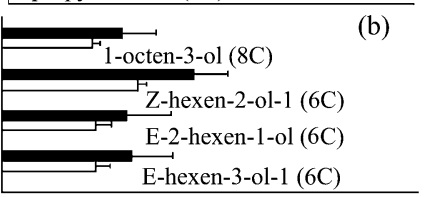

$\underset{\sim}{\longrightarrow}$

hexenal

E-2-hexen-1-al

2-pentanone

(d)

(e)

(a)

(c)

Z-hexen-3-yl acetate

)

)

)

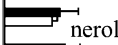

nerol

geraniol

$( \pm)$ linalool

-1 ( \pm - $\beta$-citronellol

terpineol

citronellal

图 1 亚洲小车蝗和鼓翅皱膝蝗对 37 种植物挥发性化合物的 EAG 反应 黑色示雄虫, 白色示雌虫; 标准刺激的 EAG 值为 100 . \# 示种间差异; *示性别差异

与空白刺激相比, 近端 7 节的触角片段几乎没有触角电位反应, 而远端的触角片段则可产生显 著的反应(图 3). 亚洲小车蝗和鼓翅皱膝蝗的远端触角片段的 EAG 反应无论在反应强度上, 还 是在对不同化合物的反应强弱趋势上都与其完整触角的反应没有差异. 

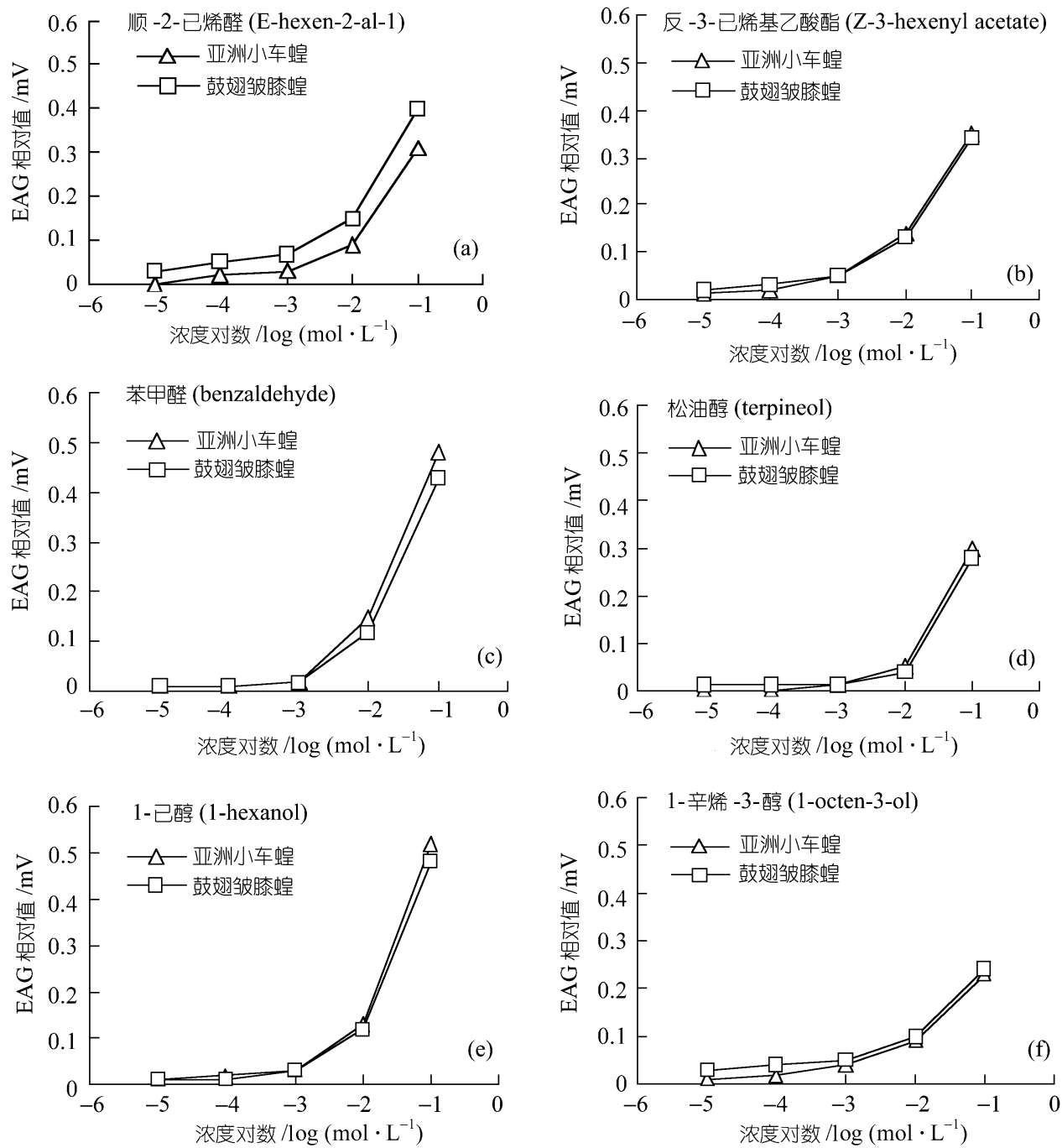

图 2 亚洲小车蝗(雌)和鼓翅皱膝蝗(雌)对 6 种植物挥发性化合物的剂量反应曲线 标准刺激的 $\mathrm{EAG}$ 值为 1

\section{3 讨论}

广食者与专食者都能对绿色植物释放的挥发性化学物质产生行为反应 ${ }^{[6]}$. 本研究所选用 的 37 种化合物常见于许多植物中, 并代表着不同化学类别. 尽管亚洲小车蝗和鼓翅皱膝蝗对 寄主植物的嗜好不同，但是它们对这些化合物的触角电位反应趋势相似，对绿叶气味化合物 的反应均高于对萜类及芳香族化合物的反应，亚洲小车蝗的反应略高于鼓翅皱膝蝗. 在许多 昆虫中都发现 6 个碳原子的醇、醛、酯可使之产生强烈的触角电位反应 ${ }^{[7,11,14 ~ 16]}$, 随着碳链长 度的增加或减少 $\mathrm{EAG}$ 反应减弱. 本实验中, 亚洲小车蝗和鼓翅皱膝蝗也不例外. 另外发现 7 个碳原子的 1-庚醇也可使这两种蝗虫产生强烈的 EAG 反应, 对具有醇、醛功能团的单萜类化 合物比其他萜类化合物的反应强，在其他许多昆虫中也有类似的结果 ${ }^{[12,15,17,18]}$.

亚洲小车蝗和鼓翅皱膝蝗对植物有不同的选择 ${ }^{[1]}$, 由于对寄主植物的生态适应, 不同食性 
的蝗虫上腭结构不同 ${ }^{[19]}$, 在嗅觉上 对各自的寄主植物气味也有一定的适 应. 陈湖海等人 ${ }^{[10]}$ 研究了这两种蝗虫 对 10 种植物气味的触角电位反应, 发 现虽然两者对这些植物气味的反应趋 势相似，但是亚洲小车蝗作为禾草专 食者, 对禾本科植物的嗅觉反应明显 高于鼓翅皱膝蝗; 鼓翅皱膝蝗为蒿草 专食者, 它对百合科山非 (Allium senescens Linn.)的 EAG 反应则显著高 于亚洲小车蝗, 而且对菊科植物气味 的反应也高于亚洲小车蝗，这表明蝗 虫可通过对寄主植物气味的辨别进 行寄主植物定位. 它们通过对寄主植 物气味多种化合物组成的气味指纹 图谱的分辨寻找寄主植物，或寄主植

亚洲小车蝗

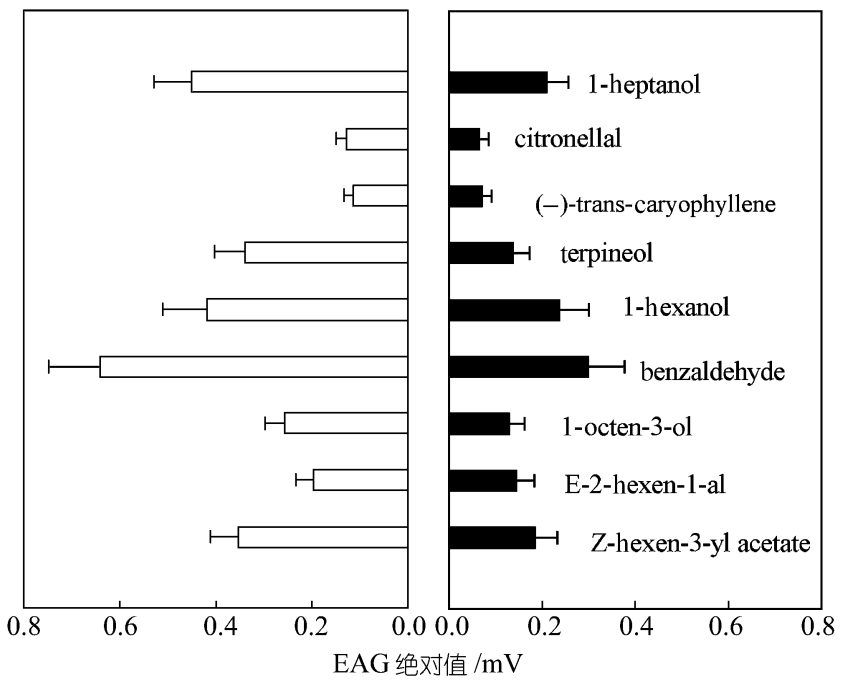

图 3 亚洲小车蝗(雌虫)和鼓翅皱膝蝗(雌虫)远端触角 片段对 9 种植物挥发性化合物的 EAG 反应 $(n=6)$ 物中某些特殊化合物成为昆虫寄主植物定位的关键 ${ }^{[16]}$.

有些植物挥发性化合物在不同浓度下可引发昆虫不同的行为或生理反应 ${ }^{[13]}$. 一些研究发 现，能在低浓度下使昆虫产生反应的化合物对昆虫在远距离的寄主定位有重要作用，而在高 浓度下使之产生反应的化合物对其近距离的寄主定位更重要 ${ }^{[20,21]}$. 亚洲小车蝗和鼓翅皱膝蝗 对高浓度的正己醇和苯甲醛产生较强反应，说明这两种化合物可能是它们寻找寄主植物时的 短距离引诱剂. 进一步阐明植物挥发性物质在昆虫与植物关系中的作用, 还需有化学物质在 植物中的分布以及相应的行为实验.

对植食性昆虫而言，嗅觉信息不仅对寄主植物定位有重要作用，而且对其寻找配偶也有 作用. 亚洲小车蝗对许多绿叶挥发气味的反应都高于鼓翅皱膝蝗, 其雄虫对绿叶挥发性化合 物、单萜、倍半萜烯的反应高于雌虫, 这些化合物可能成为雄虫在远距离的寄主定位及寻找雌 虫中的吸引物. 亚洲小车蝗有明显的性两型, 雄虫体型小于雌虫, 活动力较强, 而且雄虫的触 角感器数量多于雌虫 ${ }^{[10]}$, 因而雄虫在寻找寄主植物及雌虫时嗅觉反应更敏感. 鼓翅皱膝蝗则 没有这种性两型的现象，雄虫与雌虫的嗅觉敏感程度相似，该蝗虫对配偶的寻找可能更依赖 于声音和(或)视觉等信息. 在生殖季节，常见鼓翅皱膝蝗雄虫在距地面 $1 \sim 1.5 \mathrm{~m}$ 的上空盘旋, 振翅发声.

以植物挥发性化合物刺激亚洲小车蝗和鼓翅皱膝蝗触角近基部的片段, 均没有测到 EAG 反应, 这可能是该部分感器数量较少所致. 沙漠蝗(Schistocera gregaria (Forskål))触角上的雉 型感器、腔型感器主要集中分布在中部的触角节上 ${ }^{[22]}$, 在亚洲小车蝗和鼓翅皱滕蝗上也观察 到类似的现象, 大部分腔雉型感器分布在触角远端 $(>7$ 节)的触角节上, 只有 $0.4 \%$ 的腔雉型感 器分布在近基部的 7 节触角上(表 1), 这表明嗅觉主要是由触角远端的感器完成, 腔雉型感器 是重要的嗅觉感器. 
致谢 感谢中国科学院动物研究所严福顺研究员对本研究提供的帮助.

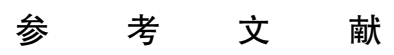

1 康 乐, 陈永林. 草原蝗虫营养生态位的研究. 昆虫学报, 1994, 37: 178 189

2 Kang L, Chen Y L, Dynamics of grasshopper communities under different grazing intensities in Inner Mongolian steppes. Entomologia Sinica, 1995, 2: 265 281

3 Kang L, Chen Y L. Multidimensional analysis of resource utilization in assemblages of rangeland grasshoppers. Entomologia Sinica, 1994, 1: 264 282

4 Blust M H, Hopkins T L. Gustatory responses of a specialist and a generalist grasshopper to terpenoids of Artemisia ludoviciana. Entomologia Experimentalis et Applicata, 1987, 45: 37 46

5 Chapman R F, Bernays E A, Wyatt T. Chemical aspects of host-plant specificity in three Larrea-feeding grasshoppers. Journal of Chemical Ecology, 1988, 14: 557 575

6 Hopkins T L, Young H. Attraction of the grasshopper, Melanoplus sanguinipes, to host plant odours and volatile components. Entomologia Experimentalis et Applicata, 1990, 56: 249 258

7 Kang L, Charlton R, Hopkins T L. Olfactory response of the grasshopper Melanoplus sanguinipes to plant odours and volatile compounds. Entomologia Sinica, 1995, 2: 136 144

8 Kafka W A. Specificity of odour-molecule interation in single cell. In: Ohloff G, Thomas A F. Gustation and Olfaction. London: Academic Press, 1971. 61 72

9 White P R, Chapman R F. Olfactory sensitivity of gomphocerine grasshoppers to the odours of host and non-host plants. Entomologia Experimentalis et Applicata, 1990, 25: 86 97

10 Chen H H, Kang L. Olfactory responses of two species of grasshoppers to plant odours. Entomologia Experimentalis et Applicata, 2000, 95: 129 134

11 Visser J H. Electroantennogram responses of the colorado beetle Leptionotarssa decemlineata to plant volatiles. Entomologia Experimentalis et Applicata, 1979, 25: 86 97

12 Ramachandran R, Khan Z R, Caballero P, et al. Olfactory sensitivity of two sympatric species of rice leaf folders (Lepidoptera: Pyralidae) to plant volatiles. Journal of Chemical Ecology, 1990, 16: 2647 2666

13 Raguso R A, Light D M, Pickersky E. Electroantennogram responses of Hyles lineata (Sphingidae: Lepidoptera) to volatile compounds from Clarkia breweri (Onagraceae) and other moth-pollinated flowers. Journal of Chemical Ecology, 1996, 22: $1735 \sim 1766$

14 Kozlowski M W, Visser J H. Host plant related properties of the antennal olfactory system in the oak flea weevil, Rynchaenus guercus. Electroantennogram study. Entomologia Experimentalis et Applicata, 1981, 30: 169 175

15 Dikens J C. Olfaction in the boll weevil, Anthonomus grandis Boh. (Coleptera: Curculionidea): electroantennogram studies. Journal of Chemical Ecology, 1984, 10: 1759 1785

16 Zhao Y X, Kang L. Role of plant volatiles in host plant location of the leafminer, Liriomyza sativae (Diptera: Agromyzidae). Physiological Entomology, 2002, 27: 103 111

17 Guerin P M, Visser J H. Electroantennogram responses of the carrot fly, Psila rosae to volatile plant components. Physiological Entomology, 1980, 5: 111 119

18 Dikens J C, Boldt P E. Electroantennogram responses of Trirhabda bacharides (Weber) (Coleoptera: Chrysomelidae) to plant volatiles. Journal of Chemical Ecology, 1985, 11: 767 779

19 Kang L, Gan Y L, Li S W. The structural adaptation of mandibles and food specificity in grasshoppers on Inner Mongolian grasslands. Journal of Orthopteral Research, 1999, 8: 257 269

20 Wickremasinghe M G V, Van Emden H F. Reactions of adult female parasitoids, particularly Aphidius rhopalosiphi, to volatile chemical cues from the host plants of their aphid prey. Physiological Entomology, 1992, 17: 297 304

21 Elzen G W, Williams H J, Vinson S B. Wind tunnel flight responses by the hymenopterous parasitoid Campoletis sonorensis to cotton cultivars and lines. Entomologia Experimentalis et Applicata, 1986, 42: 285 289

22 Ochieng S A, Hallberg E, Hansson B S. Fine structure and distribution of antennal sensilla of the desert locust, Schistocerca gregaria (Orthoptera: Acrididae). Cell \& Tissue Research, 1998, 291: 525 536 